\title{
Productivity begets less phylogenetic diversity but higher uniqueness than expected
}

\author{
Wilfried Thuiller ${ }^{1}$ (D) | Dominique Gravel ${ }^{2}$ | Gentile Francesco Ficetola $a^{1,3}$ | \\ Sébastien Lavergne ${ }^{1}$ | Tamara Münkemüller ${ }^{1}$ | Laura J. Pollock $^{1}$ | \\ Niklaus E. Zimmermann ${ }^{4}$ | Florent Mazel ${ }^{5}$
}

${ }^{1}$ Univ. Grenoble Alpes, CNRS, Univ. Savoie Mont Blanc, LECA, Laboratoire d'Écologie Alpine, F-38000 Grenoble, France

${ }^{2}$ Département de biologie, Université de Sherbrooke, Sherbrooke, Canada

${ }^{3}$ Department of Environmental Science and Policy, Università degli Studi di Milano, Milano, Italy

${ }^{4}$ Swiss Federal Research Institute WSL, Birmensdorf, Switzerland

${ }^{5}$ Department of Botany and Biodiversity Research Centre, University of British

Columbia, Vancouver, Canada

\section{Correspondence}

Wilfried Thuiller, Univ. Grenoble Alpes, CNRS, Univ. Savoie Mont Blanc, LECA, Laboratoire d'Écologie Alpine, F-38000 Grenoble, France.

Email: wilfried.thuiller@univ-grenoble-alpes.fr

\section{Funding information}

Agence Nationale de la Recherche, Grant/ Award Number: ANR-18-EBI4-0009; Swiss National Foundation, Grant/Award Number: 20BD21_184131/1

Editor: Damaris Zurell

\begin{abstract}
Aim: The positive effect of primary productivity on animal species richness is one of the most conspicuous ecological features on Earth. However, less is known about the relationship between ecosystems primary productivity and the evolutionary history of biota. Here, we analyse how global primary productivity relates to the phylogenetic structure of vertebrate assemblages, and to the distribution of the most distinct lineages and recently diversified clades.

Location: Global.
\end{abstract}

Taxon: Amphibians, birds and mammals.

Methods: We calculated relative phylogenetic diversity (i.e. phylogenetic diversity corrected for species richness), standardized effect size of the richness of top $25 \%$ evolutionary distinct species and of top $25 \%$ species-level lineage diversification rates. We related these three metrics to mean net primary productivity (NPP) at the global scale, and for each zoogeographic region. We also tested the influence of the spatial scaling of species pool on the overall analyses (global, hemispheric and zoogeographic regions-based species pools).

Results: Phylogenetic diversity (corrected for species richness) of the three taxa decreases with NPP (in contrast with species richness) and varies considerably in space. High productivity sites harbour more closely related species than low productivity sites consistently across zoogeographic zones. However, the phylogenetically most distinct species are also found in high productivity sites, while the top most rapidly diversifying lineages are found in the least productive sites. Modifying the spatial extent of the species pool did not affect the results much.

Conclusions: Benign conditions in high productivity sites (a) result in denser niche packing and thus allow for the coexistence of many closely-related species and (b) protect the persistence of evolutionary distinct species. Low productivity sites may harbour fewer, more distinct and temporarily more variable niches that allow maintenance of unique lineages for longer periods of time.

\section{KEYWORDS}

amphibians, birds, diversity-productivity relationship, global scale, mammals, phylogenetic distinctiveness, phylogenetic diversity 


\section{1 | INTRODUCTION}

The increase in species richness with increasing primary productivity is one of the most consistent patterns in ecology, and one of few ecological patterns that holds across scales and vertebrate taxa (Evans, Warren, \& Gaston, 2005), as well as through geological time (Fritz et al., 2016). The processes behind this richness-productivity relationship have long been debated on the grounds of several ecological and evolutionary hypotheses on why there are more species in productive areas. From an ecological perspective, productivity could directly impact the number of species through supporting higher densities, greater ecological heterogeneity, higher specialization and larger total niche space (Brown, 2014; Currie et al., 2004; Evans et al., 2005; Storch, Bohdalková, \& Okie, 2018; Wright, Currie, \& Maurer, 1993; Wright \& Rohde, 2013). However, from an evolutionary perspective, productivity could also influence diversification by either decreasing species' extinction rates or by enabling higher in situ speciation rates due to higher population densities and thus faster rates of molecular evolution (Allen \& Gillooly, 2006; Rosenzweig, 1995), stronger biotic interactions or higher ecological opportunities (Rabosky et al., 2018; Schemske, Mittelbach, Cornell, Sobel, \& Roy, 2009; Schluter \& Pennell, 2017). In all cases, evolutionary trajectories were substantially altered by periods of historical environmental stability and by glaciation cycles in some regions, which are relevant to understanding the productivity-diversity relationship. For instance, the latitudinal gradient hypothesis posits that climatic variation (e.g. glaciation cycles) in temperate regions may have led to large-scale extinction events and potentially enhanced speciation (Weir \& Schluter, 2007). This would imply that regions of low productivity and major glaciations could harbour species assemblages that have originated largely from speciation during the interglacial phases. The different ecological and evolutionary explanations cannot be disentangled when focussing simply on species (or genus) richness because they all hypothesize more species in highly productive areas. Indeed, this is only when combining species diversity with additional biodiversity metrics that we get an understanding of the relevant processes.
Here, we re-examine the productivity-diversity relationship in the light of the evolutionary history of vertebrate species and the resulting phylogenetic diversity patterns. We provide a novel understanding of why increasing primary productivity leads to higher diversity in some regions but not in others.

The above mentioned ecological and evolutionary processes are expected to result in a broad range of geographic and phylogenetic patterns of biodiversity that we can observe today. This includes both the diversity of species assemblages in local areas (so we can ask: are the species in an assemblage phylogenetically closely or rather distantly related?) and characteristics of individual species (so we can ask: does a species belong to a rapidly diversifying group with many closely related species or does it belong to a phylogenetically distinct, species poor lineage?). For example, if net primary productivity (NPP) promotes diversification through increased in situ speciation, we then would expect to see increasing densities of closely related species belonging to rapidly radiating clades in local species assemblages (Table 1, 1st row/3rd column). However, if NPP promotes diversification through reduced extinction rates, we would also expect to observe species that are phylogenetically more distinct, as "old" lineages could have survived (Table 1, 1st row/3rd column \& and 2nd row/4th column). In contrast and from an ecological perspective, if high NPP regions increase competitive interactions between species with similar niches (Bertness \& Callaway, 1994), and species' niches are phylogenetically conserved (Lavergne, Mouquet, Thuiller, \& Ronce, 2010), we would expect significantly higher phylogenetic diversity (when correcting for species richness) and higher numbers of phylogenetically distinct species in high compared to low NPP regions (Table 1, 1st row/4th column, \& 2nd row/4th column).

Studying the multiple imprints of ecological and evolutionary processes on species' assemblages can cast novel insights into our understanding of why species richness often scales positively with productivity. Here, we propose to complement the widely reported positive species richness-productivity relationship by documenting how productivity correlates with phylogenetic

TAB LE 1 Phylogenetic diversity metrics and associated interpretations of the correlation with net primary productivity (NPP)

\begin{tabular}{|c|c|c|c|c|}
\hline & \multicolumn{2}{|l|}{ Metric meaning } & \multicolumn{2}{|l|}{ Metric correlation with NPP } \\
\hline & Low (negative) values & High (positive) values & Negative & Positive \\
\hline Relative PD & $\begin{array}{l}\text { Closely related species } \\
\text { co-occur }\end{array}$ & Distantly related species co-occur & $\begin{array}{l}\text { High NPP enables tight } \\
\text { niche packing or promotes } \\
\text { diversification }\end{array}$ & $\begin{array}{l}\text { High NPP increases } \\
\text { competition of close } \\
\text { species or slows down } \\
\text { diversification }\end{array}$ \\
\hline $\begin{array}{l}\text { SES of top } \\
\text { ED }\end{array}$ & $\begin{array}{l}\text { Evolutionary distinct } \\
\text { species are rare in the } \\
\text { assemblage }\end{array}$ & $\begin{array}{l}\text { Evolutionary distinct species are } \\
\text { frequent in the assemblage }\end{array}$ & $\begin{array}{l}\text { High NPP decreases the sur- } \\
\text { vival of distinct species }\end{array}$ & $\begin{array}{l}\text { High NPP promotes } \\
\text { the survival of distinct } \\
\text { species }\end{array}$ \\
\hline $\begin{array}{l}\text { SES of top } \\
\text { DR }\end{array}$ & $\begin{array}{l}\text { Species belonging to clades } \\
\text { with high diversifica- } \\
\text { tion rates are rare in the } \\
\text { assemblage }\end{array}$ & $\begin{array}{l}\text { Species belonging to clades with } \\
\text { high diversification rates are } \\
\text { frequent in the assemblage }\end{array}$ & $\begin{array}{l}\text { High NPP decreases diversi- } \\
\text { fication in-situ or decrease } \\
\text { the survival of species } \\
\text { belonging to fast diversify- } \\
\text { ing clades }\end{array}$ & $\begin{array}{l}\text { High NPP promotes } \\
\text { diversification in situ or } \\
\text { promotes the survival of } \\
\text { species belonging to fast } \\
\text { diversifying clades }\end{array}$ \\
\hline
\end{tabular}

Note: Relative PD relates to relative phylogenetic diversity, SES of top ED to standardized effect size of richness of the top $25 \%$ evolutionarily most distinctive species, and SES of top DR to standardized effect size of richness of top $25 \%$ species-level lineage diversification rates. 


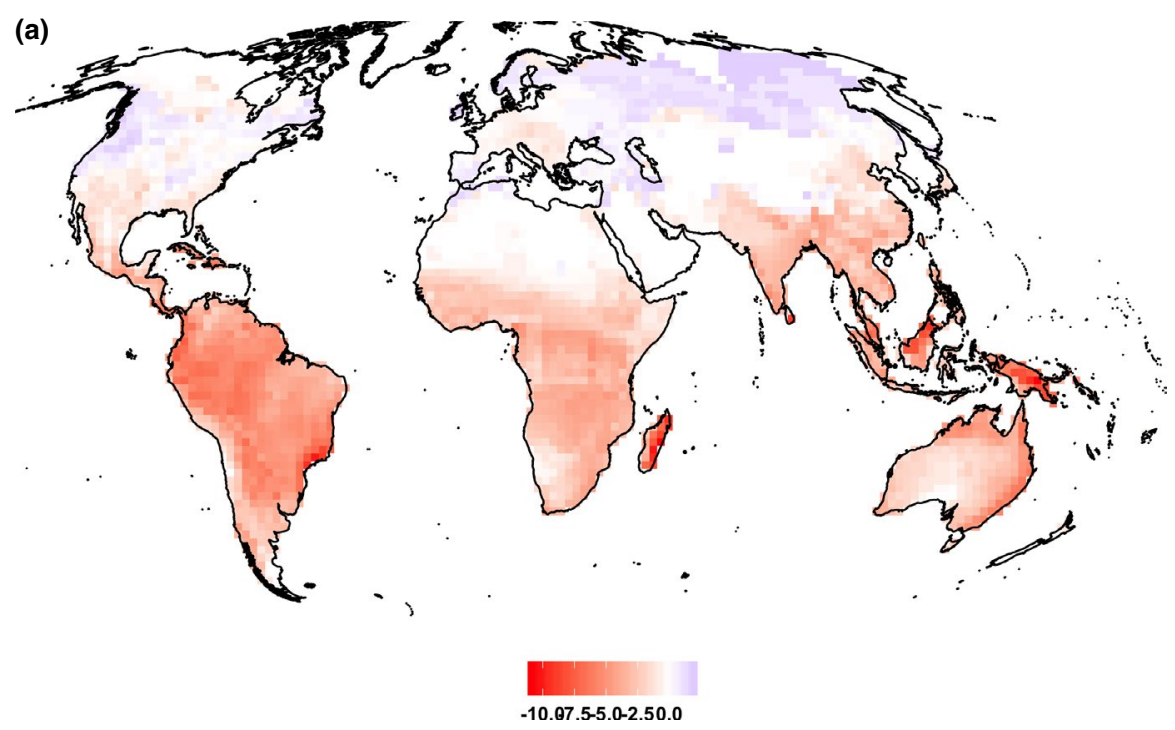

(b)

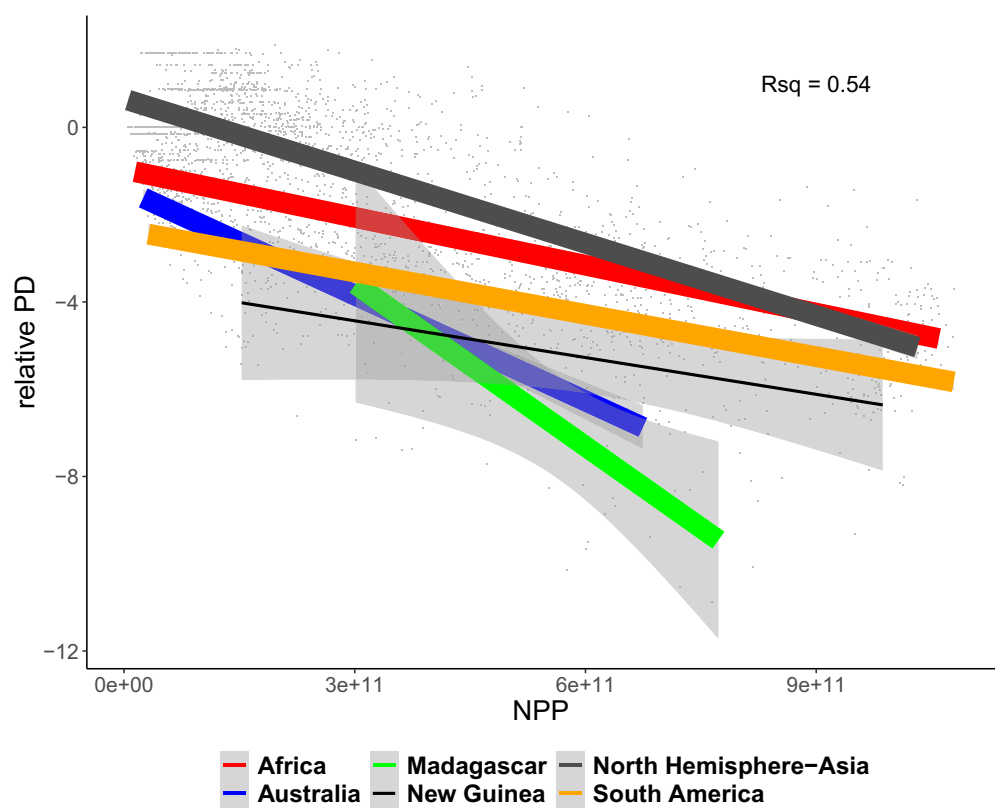

FIGURE 1 Maps of relative phylogenetic diversity (rPD) and the relationships with net primary productivity (NPP). A-B: amphibians, C-D: birds, E-F: mammals. Plots represent the global relationship estimated for the available trees (100 for birds and mammals, 1 for amphibians) represented as grey dots, while different colours represent the relationships for the different zoogeographic regions. The $R^{2}$ displayed on the play represent the explained variance of the global relationship between rPD and NPP (see Figure S3). The width of the lines is proportional to the (mean) R square of the relationship between rPD and NPP calculated for each zoogeographic region (narrow: $R^{2} \leq 0.1$, medium: $0.1<R^{2}<0.3$, large: $R^{2} \geq 0.3$ ). The grey shading around the regression lines represent the $95 \%$ confidence intervals of the regressions. The distributions of the zoogeographic regions are presented in Figure S2

diversity, the richness of top evolutionary distinct species and the richness of top species-level lineage diversification rates. As these three complementary measures are inherently influenced by species richness, they need to be corrected by species richness to be useful for further interpretation. Thus, we here analyse how the worldwide spatial distribution of richness corrected phylogenetic diversity (i.e. relative phylogenetic diversity, rPD hereafter), the relative richness of the top $25 \%$ most evolutionarily distinct (ED) species and the relative richness of the top $25 \%$ species-level lineage diversification rates (DR) in terrestrial amphibians, birds and mammals relates to the distribution of NPP. We considered NPP since it is a suitable measurement of primary energy production metric for investigating consumer species-energy relationships and consistency in productivity-richness studies (Evans, Straw, \& Watt, 2002). We also tested whether patterns observed at the global scale hold within zoogeographical regions (regions harbouring relatively homogenous species assemblages from a taxonomic and phylogenetic viewpoint [Holt et al., 2013]). We thus conducted this analysis at both the global scale and within the different zoogeographic regions of the world (Holt et al., 


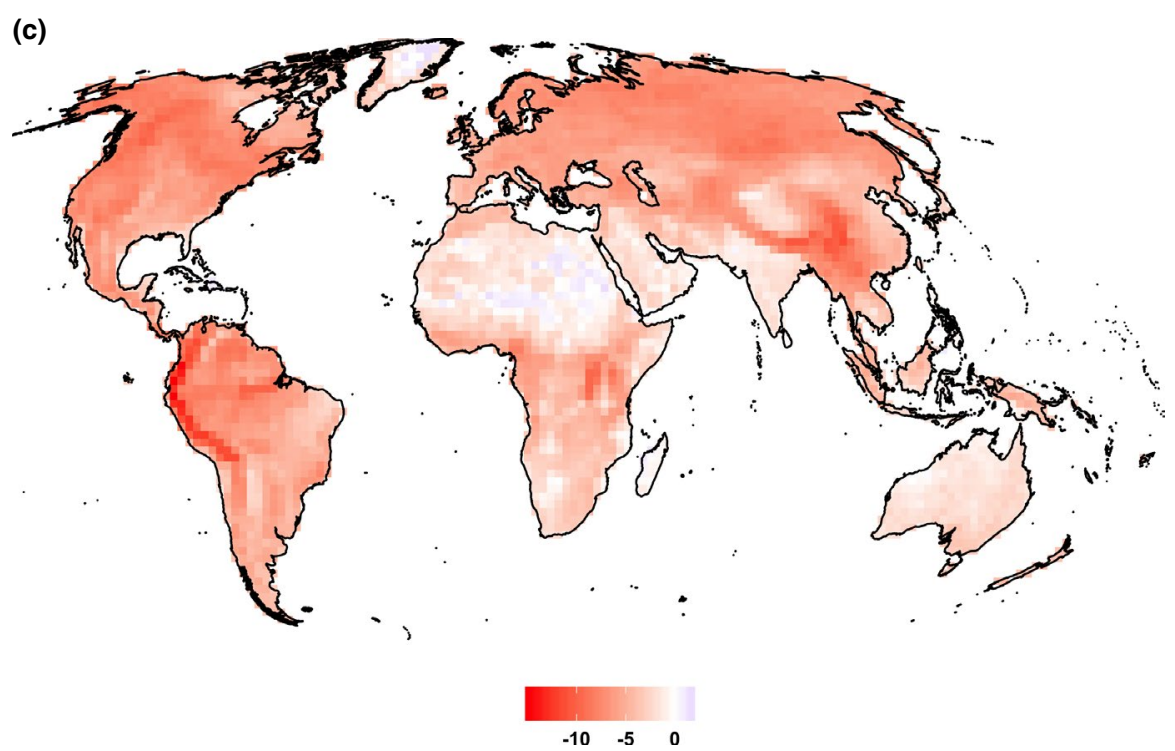

(d)

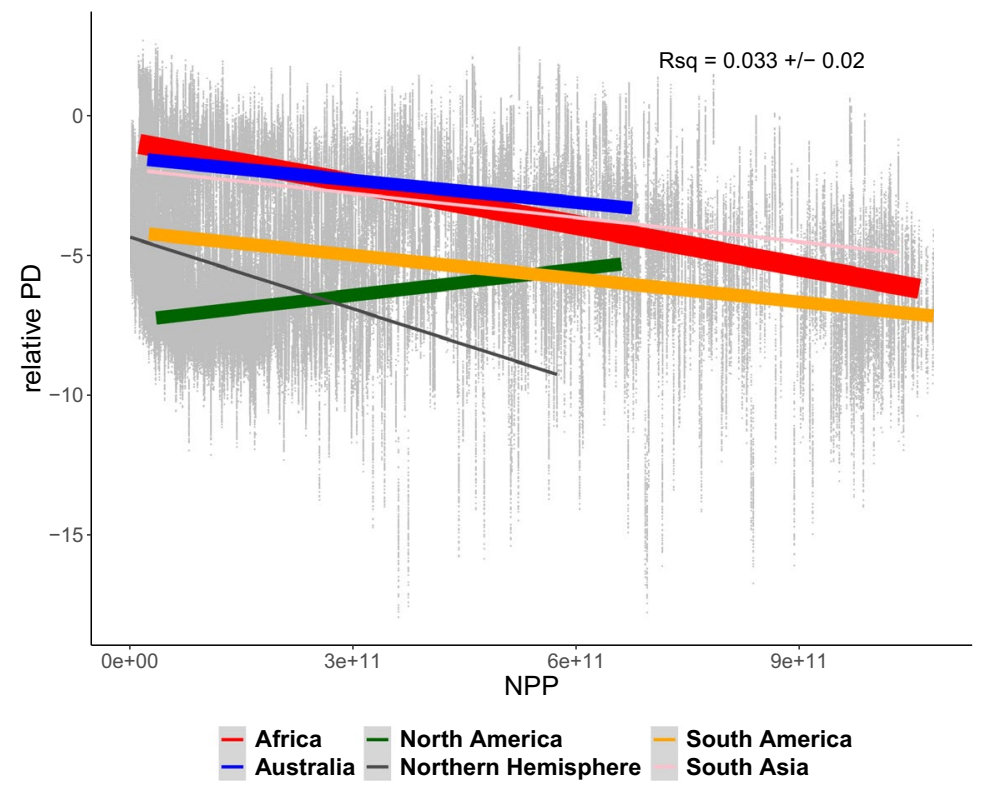

FIGURE 1 (Continued)

2013) but also by varying the spatial extent of the species pool considered when calculating rPD (Kissling et al., 2012). Finally, we tested whether those trends are driven by the response of specific lineages within the three main vertebrate taxa considered.

We addressed these objectives by using geographic range maps of amphibians, birds and mammals of the world from the IUCN Red List Assessment and from BirdLife (at $200 \mathrm{~km}$ resolution), combined with comprehensive sets of species-level phylogenies for the three groups.

\section{MATERIALS AND METHODS}

\section{1 | Distribution data}

We used the distribution maps provided by the Amphibian and Mammal Red List Assessment (http://www.iucnredlist.org/, accessed in September 2017) for 5,547 and 4,616 species, respectively.
For birds, breeding ranges distribution maps were extracted from BirdLife (http://www.birdlife.org/, accessed in September 2017) for 9,993 species. We transformed the original shapefiles into a $200 \times 200 \mathrm{~km}$ grid (equal-area projection), which is regularly used at the global scale (Ficetola et al., 2014; Hurlbert \& Jetz, 2007; Pollock, Thuiller, \& Jetz, 2017), by intersecting the polygons of each species and the grid. As soon as a portion of a polygon hit a pixel, the species was considered present. The total number of grid cells was 3,646. Domestic and fully aquatic species were excluded from the analysis.

\section{2 | Net primary productivity}

NPP was extracted from the Socioeconomic Data and Applicatio ns Center - A data centre in NASA's Earth Observing System Data and Information System. NPP is measured in units of elemental carbon (grams of carbon per year per pixel) and represents the primary 
(e)

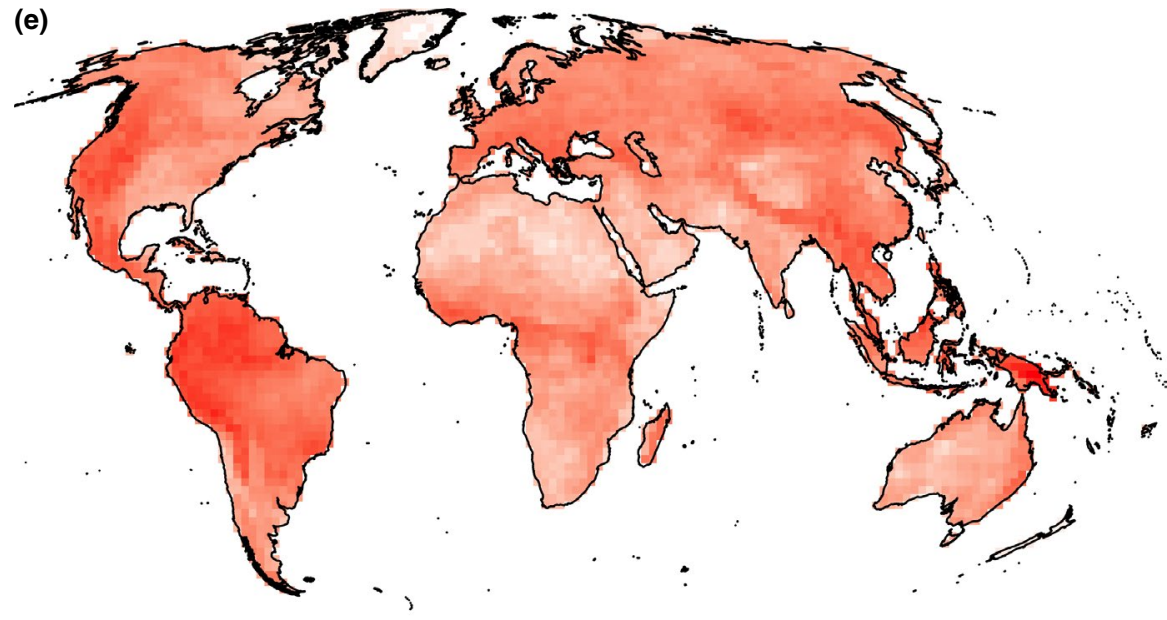

$-10.0-7.5-5.0-2.50 .0$

(f)

FIGURE 1 (Continued)

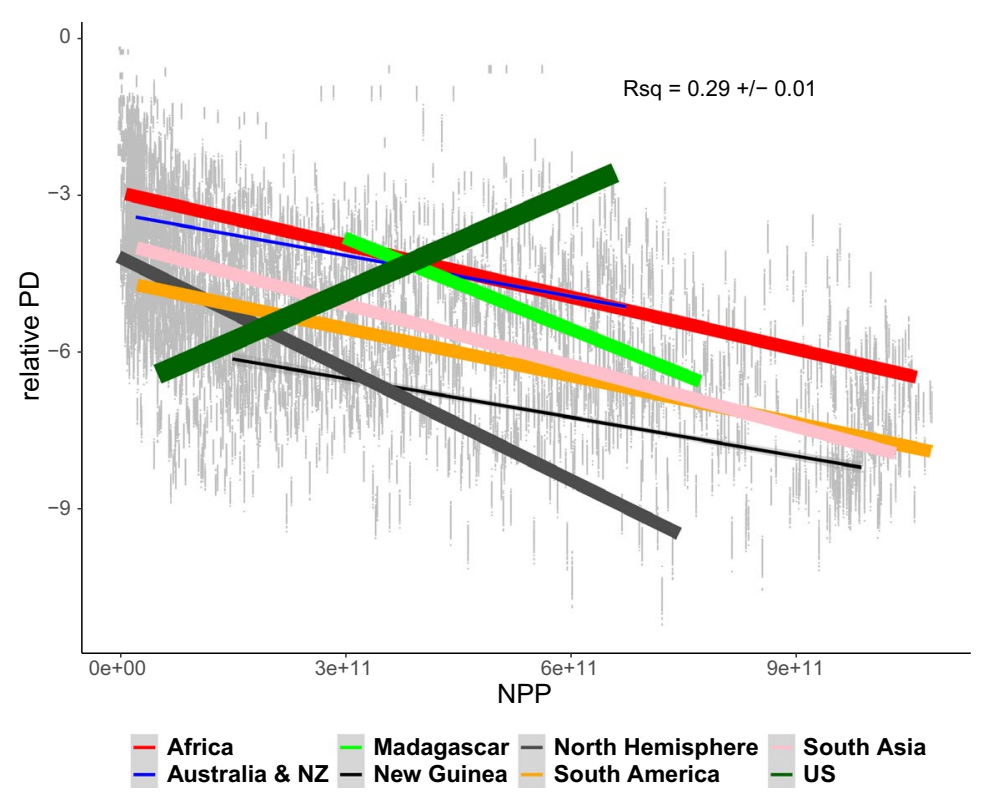

energy source for secondary productivity. This data set is distributed by the Columbia University Center for International Earth Science Information Network (CIESIN, Imhoff et al., 2004; Imhoff \& Bounoua, 2006)).

\section{3 | Zoogeographic regions}

Holt et al. (2013) defined zoogeographic regions as regions of evolutionarily unique assemblages, with distinct regionalization for the three classes. The classification of vertebrate assemblages into zoogeographic units was done to get between six (amphibians and birds) and height regions (mammals) (see Figure S2 for the distribution and naming of the zoogeographic regions). Regions were then converted to a raster with a $200 \mathrm{~km}$ resolution following the same rule than for the species' polygons.

\section{4 | Phylogenetic trees}

We used a random set of 100 time-calibrated, ultrametric phylogenetic trees from (Bininda-Emonds et al., 2007; Fritz, BinindaEmonds, \& Purvis, 2009) and from (Jetz \& Fine, 2012), respectively for both mammals and birds. We updated the mammal phylogenetic trees by replacing the Carnivora clade with a highly resolved supertree published more recently (Nyakatura \& Bininda-Emonds, 2012). For amphibians, we used the single supertree available for all amphibians of the world (Isaac, Redding, Meredith, \& Safi, 2012).

\section{5 | Phylogenetic metrics}

Phylogenetic diversity (PD) was calculated for each single pixel as "the branch length sum of all branches that are members of the 

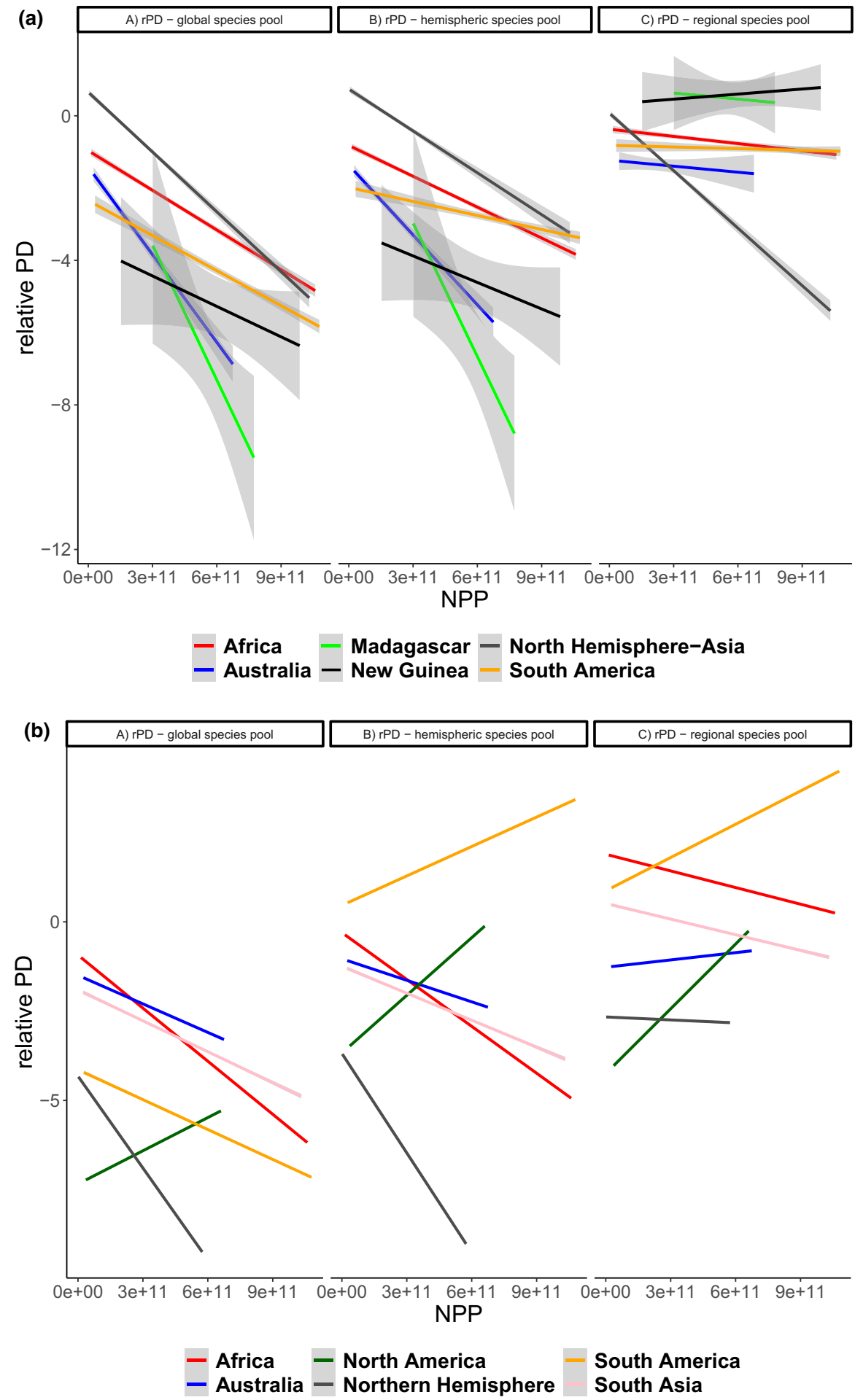

FIGURE 2 Effect of the sampling pool extent on the global relationship between relative PD and net primary productivity. A: amphibians, B: birds, C: mammals. Plots represent the global relationship estimated for the available trees (100 for birds and mammals, 1 for amphibians) represented as grey dots, while different colours represent the relationships for the different zoogeographic regions. The grey shading around the regression lines represents the $95 \%$ confidence intervals of the regressions. The distributions of the zoogeographic regions are presented in Figure S2

corresponding minimum spanning path", in which 'branch' is a segment of a tree, and the minimum spanning path is the minimum patristic distance between nodes including the roots (Faith, 1992, 2002). PD was estimated using each of the 100 trees available (for all groups except for amphibians where a single tree was used). To calculate the richness-controlled version of PD (called relative PD hereafter, rPD), we used the "PhyloMeasures" package in R (Tsirogiannis \& Sandel, 2016). For each single assemblage (pixel in this study), the 


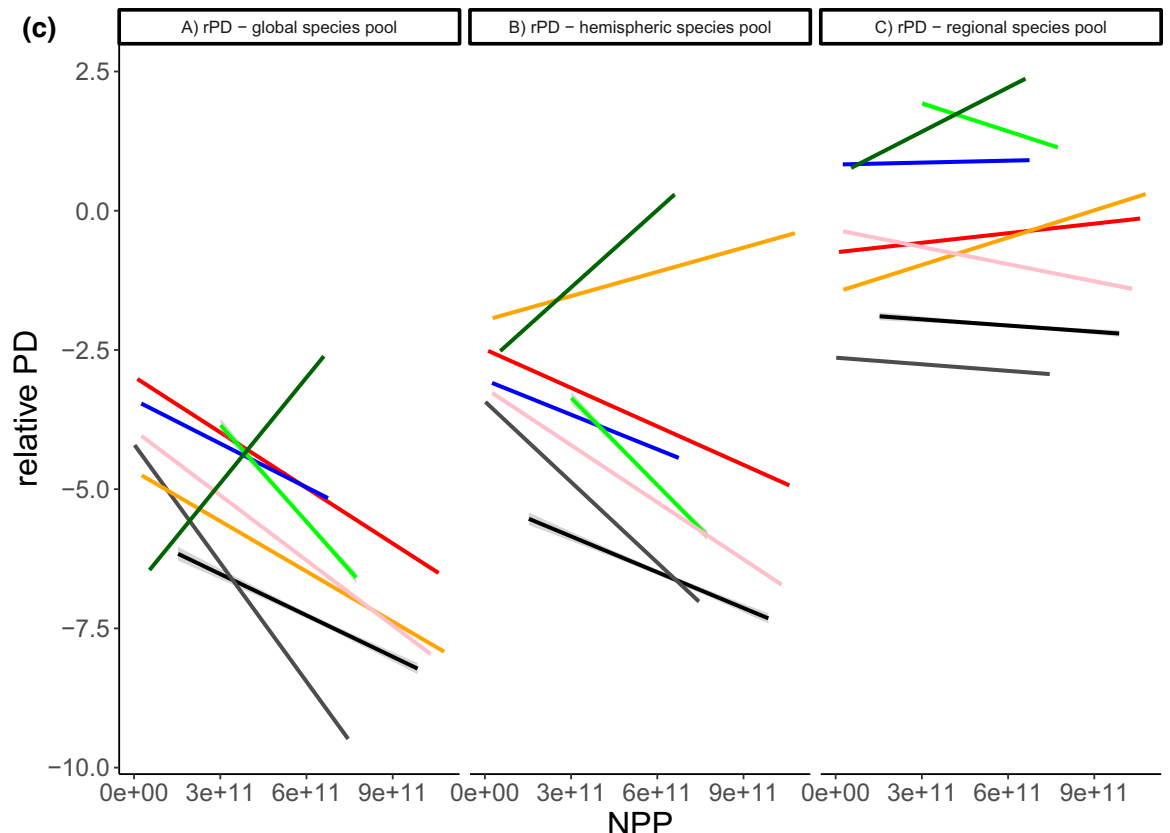

NPP

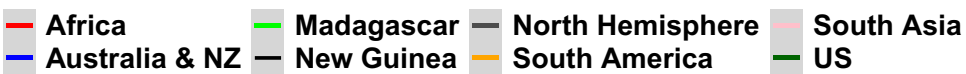

FIGURE 2 (Continued)

observed PD value is compared to an expected distribution of possible PD values derived from a particular null model. In our case, we used a null model where the species richness of the assemblage, the species pool phylogenetic tree topology and branch lengths are held constant but tip labels are shuffled (see below for various definition of the species pool). The rPD value is obtained by subtracting the mean expected PD and then dividing it by the expected PD standard deviation. Note that these rPD values are also sometimes approximated using a randomization procedure (e.g. randomly shuffling the tree tip labels 1,000 time to compute the expected PD distribution). However, the exact rPD values provided by the "PhyloMeasures" R package is preferred here because of reduced computational time.

We measured species evolutionary distinctiveness (ED) as the sum of the branch length from the species tip to the root of the tree divided by the number of species subtended to each branch (function evol. distinct in R package "picante", measure "equal-split" (Redding, Mazel, $\&$ Mooers, 2014). We measured species-level lineage diversification rates (DR) as the inverse of the species' distinctiveness measure (see Jetz, Thomas, Joy, Hartmann, \& Mooers, 2012 for a complete description of the measure and its relationships with traditional clade level diversification rates).

Richness of the top most evolutionarily distinct species (top ED) and of the highest species-level lineage diversification rates (top DR) was computed as the number of species that belong to the top $25 \%$ of each of the two classes. Since these measures correlate positively with total species richness by pure sampling effects, we ran a null model in which the distinctiveness and diversification measures were randomised among species. The richness of the top $25 \%$ species was then re-calculated. The null model was repeated
999 times and the standardized effect size (SES) in richness of the top $25 \%$ evolutionary distinctiveness (SES of top ED) and top $25 \%$ species-level lineage diversification rates (SES of top DR) was calculated by subtracting the mean richness and dividing it by the standard deviation of this measure. Note that while ED and DR are mathematically linked by calculation, this is not the case when focusing on the richness of the standardized effect size of the top $25 \%$ species from each group and there are no a priori expectations on their relationships.

\subsection{Spatial extents for the sampling pools}

The three metrics (rPD, SES of top ED and SES of top DR) were initially calculated using a global species pool. In other words, the analytical solution for rPD and the null models for SES of top ED and top DR considered that under random expectation, every species could occur everywhere, independent of dispersal constraints and historical contingencies. Since a global species pool might seem too liberal, we also calculated the three metrics for two other species pools following (Kissling et al., 2012). In the first case, we considered a hemispheric species pool "New World" and "Old World") and, in the second case, we considered the zoogeographic regions themselves. Practically, rPD, SES of top ED and top DR were thus also calculated against random expectation coming from the appropriate species pool. For instance, for pixels occurring in Europe, the species pool for the hemispheric case was "Old World", and North Hemisphere for the zoogeographic species pool. Varying the extent of the species pool allows for testing whether, within a continent or a zoogeographic region, 


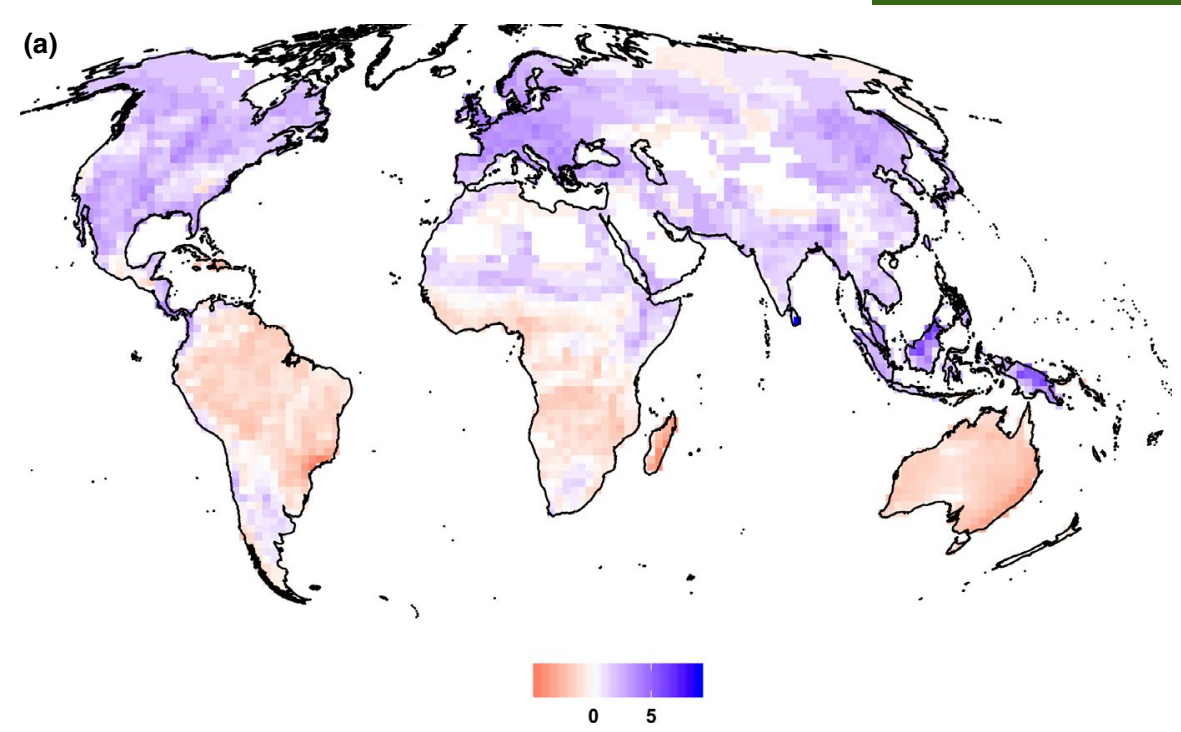

(b)

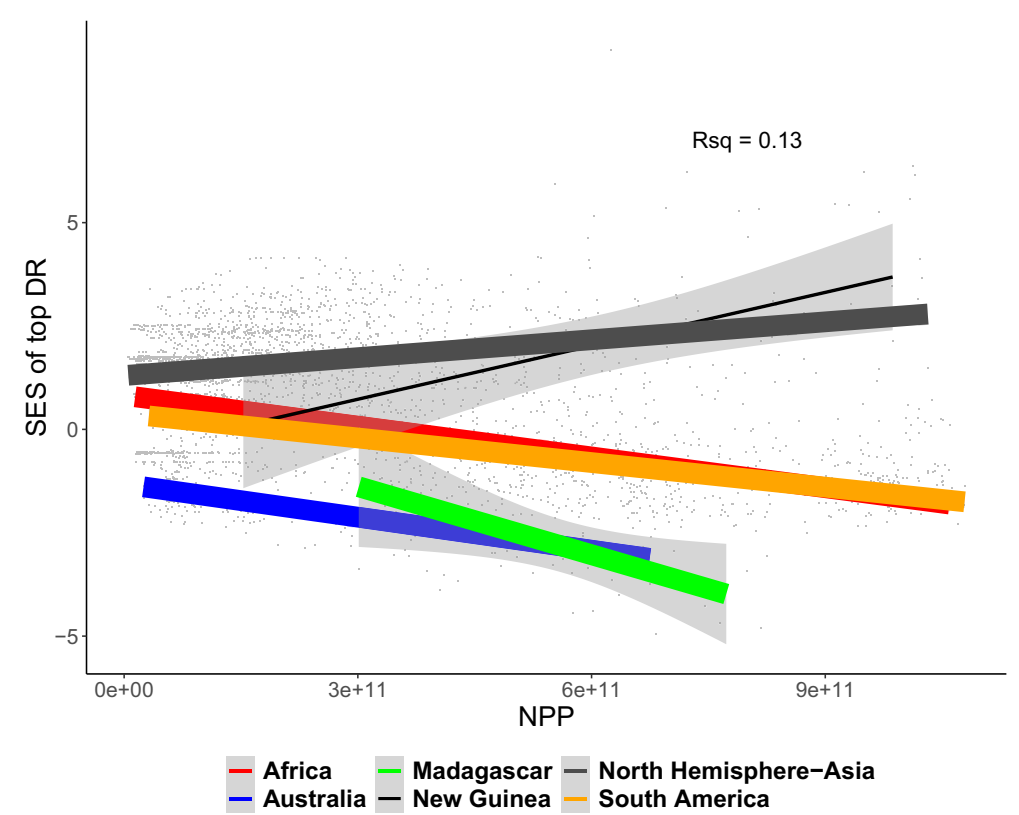

FIGURE 3 Maps of the standardized effect size of richness of the top 25\% highest species-level lineage diversification rates (SES of top DR) and the relationships with net primary productivity (NPP). A-B: amphibians, C-D: birds, E-F: mammals. Plots represent the global relationship estimated for the available trees (100 for birds and mammals) represented as grey dots, while different colours represent the relationships for the different zoogeographic regions. The width of the lines is proportional to the (mean) $R$ square of the relationship (narrow: $R^{2} \leq 0.1$, medium: $0.1<R^{2}<0.3$, large: $R^{2} \geq 0.3$ ). The grey shading around the regression lines represents the $95 \%$ confidence intervals of the regressions. The distributions of the zoogeographic regions are presented in Figure $S 2$

the relationship between our three metrics and NPP widely differ or not, with consequences for the interpretation of the observed patterns (Kissling et al., 2012).

\section{7 | Statistical analyses}

Standard ordinary least square regressions were run between rPD, SES of top ED, SES of top DR, and NPP at the global scale, and for each of the zoogeographic regions. We then extracted the adjusted $R^{2}$ values of the regressions. For mammals and birds, regression analyses were carried out for the 100 available trees. We thus reported mean $R^{2}$ and the associated standard errors. In the main text, we represented the relationship between NPP and our three metrics per zoogeographical regions with a global species pool for Figures 1,3 and 4 , and while varying the spatial extent of the species pool in Figure 2.

\section{3 | RESULTS}

rPD strongly varied in space and between the different groups (Figure 1). A striking common result among the three taxa was 

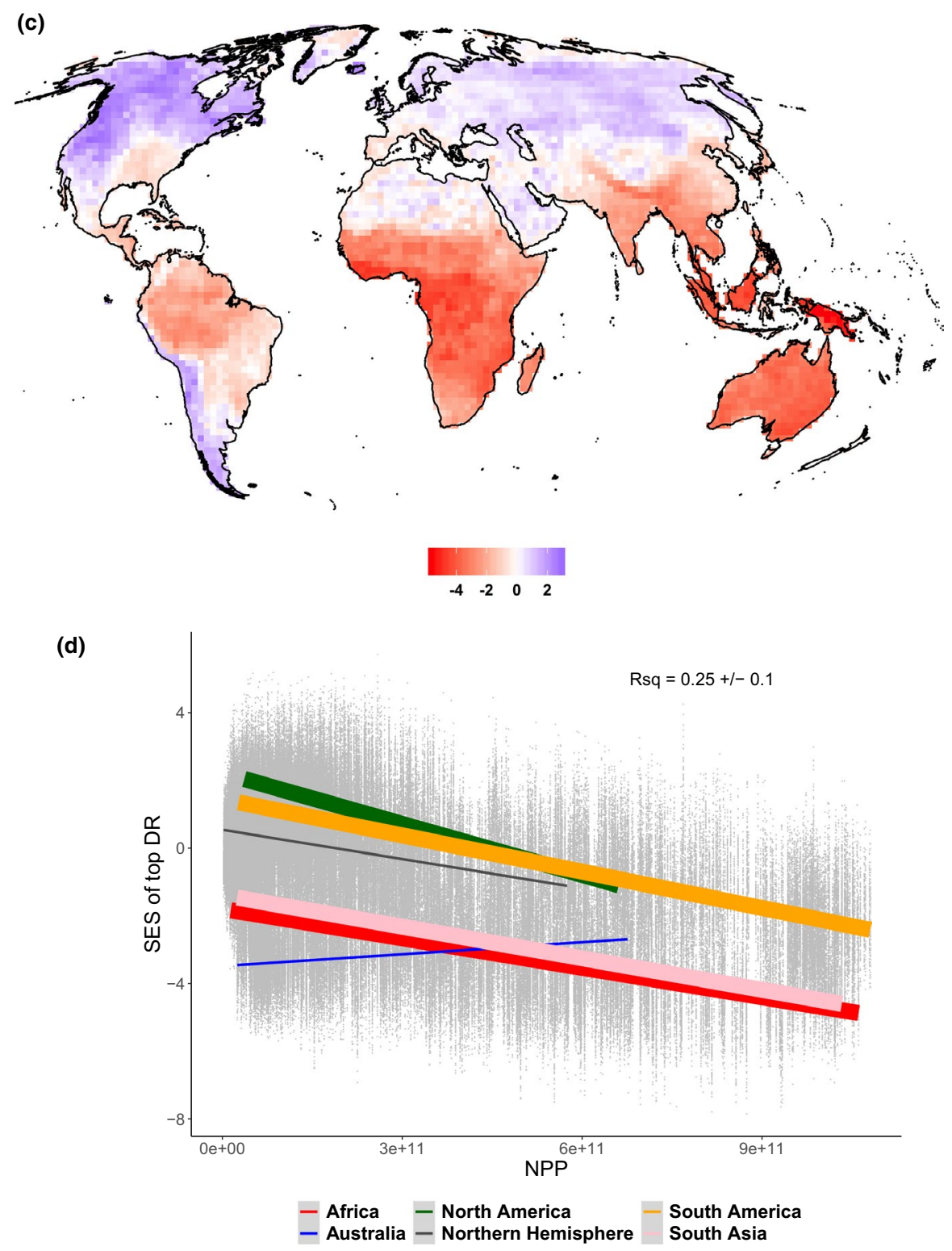

FIGURE 3 (Continued)

that rPD took generally negative values across the globe (i.e. lower than the expected PD given the species richness of the assemblage). For both birds and mammals, less than $1 \%$ of the cells were actually positive, against $\sim 20 \%$ for amphibians. This was expected given the spatial structuring of phylogenetic groups at global scales (Holt et al., 2013), which implies that local assemblages harbour less PD than randomly expected (e.g. Mazel et al., 2015). Some regions consistently host much lower PD than expected, like Indonesia and South America (notably around the Andes). Those regions either harbour relatively closely related species that belong to a single group in the phylogeny or several distinct groups distributed across the phylogeny. Group specific results showed that $\mathrm{rPD}$ of mammals and amphibians was negatively related to NPP (Figure 1 and Figure S3 for the general trends with $R^{2}=0.54$ and 0.29 for amphibians and mammals, respectively, Table S1A,B), with the lowest peaks in Madagascar, south-east Brazil and Indonesia for amphibians and in western US, western South-America and Indonesia for mammals. Thus, the most phylogenetically diverse assemblages (with respect to species richness) were consistently found in areas with low NPP. This result was consistent across the 100 phylogenetic trees analysed for mammals (data limitations prevented this test for amphibians). In contrast, rPD of birds was the lowest in the Andes, Himalaya and northern America, and was weakly negatively related to NPP $\left(R^{2}=0.03\right)$, irrespective of phylogenetic uncertainty (Figure 1, Figure S3, Table S1B).

Focusing on each zoogeographical region reveals diverging distribution patterns in birds compared to the other groups. While for birds there was by tendency a negative relationship between rPD and NPP in the five regions $\left(R^{2}=0.41\right.$ for 


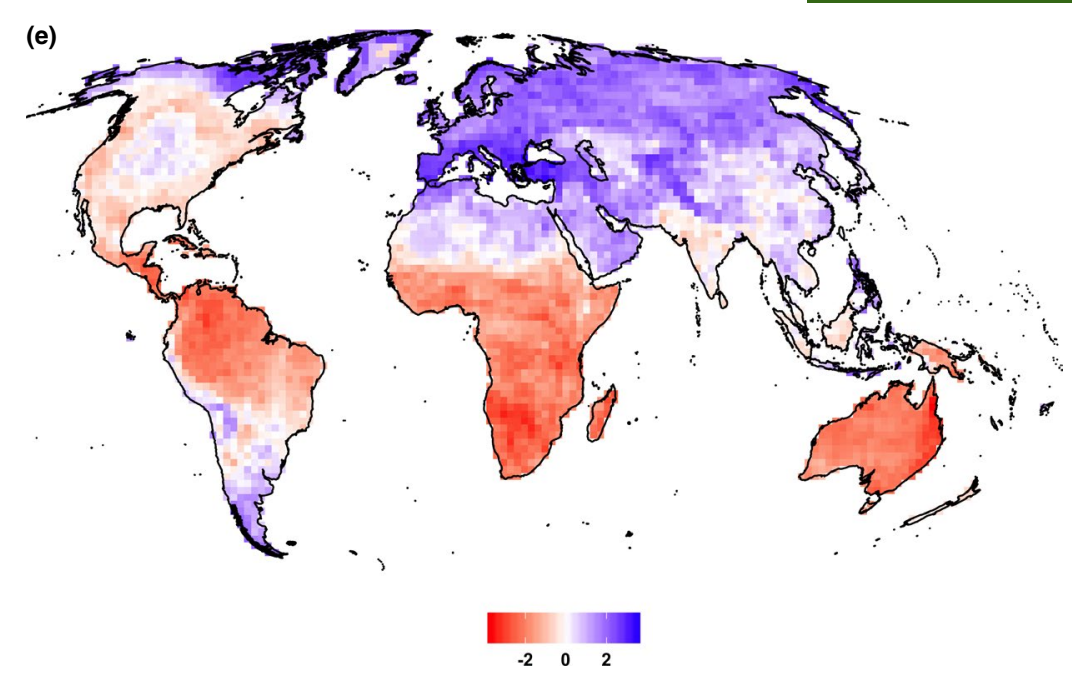

(f)

FIGURE 3 (Continued)

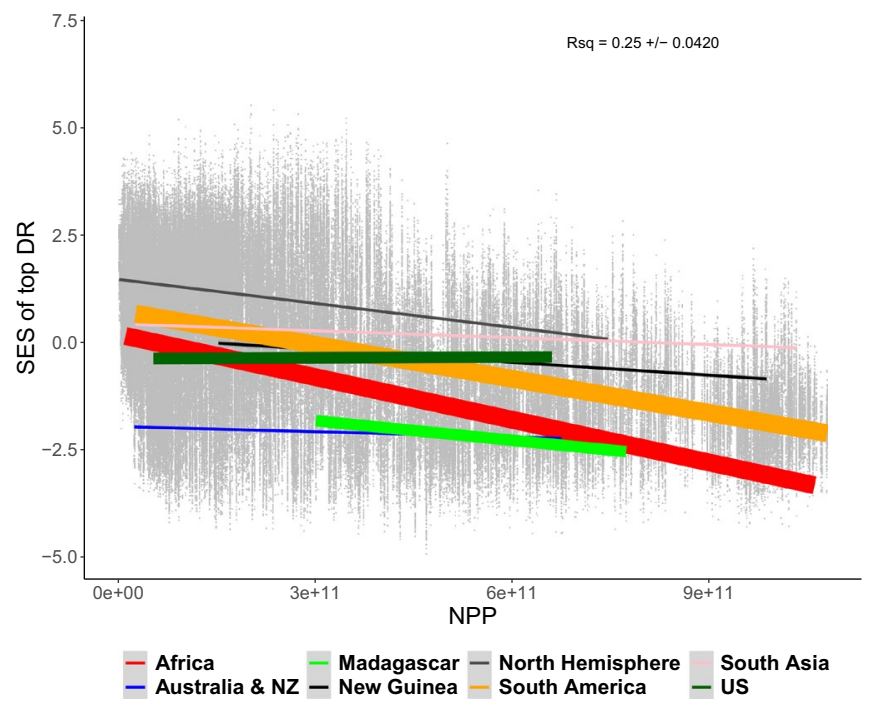

Africa, Table S1B), a single large region ("North America") displayed a weak but positive relationship between rPD and NPP (Figure 1, Table S1B). This relatively large outlier region explains the globally weak relationship between rPD and NPP for birds. Interestingly, a similar observation occurred for mammals for the "US" region. However, as this region is relatively small, it did not change the entire relationship much. In summary, the relationship between rPD and NPP was consistently negative both at the global and at the zoogeographic region scales, except for a zoogeographic region around North America for both birds and mammals (Table S1).

The observed relationship between NPP and evolutionary history was not constant across major lineages (Figure S4A-C). For amphibians, the three orders (Anura, Gymnophiona and Caudata) showed a coherent distribution of evolutionary history across the different zoogeographical regions (Figure S4A). However, for both birds and mammals, our analyses show that some particular orders diverge from the average relationship (Figure S4B,C). For birds, the rPD of Passeriformes and Psittaciformes was strongly negatively correlated with NPP
(Figure S4B), while for mammals the relationship between rPD and NPP was even positive for one group (Cetartiodactyla). Striking differences appeared between orders within zoogeographic regions. The positive relationship between rPD and NPP in "US" and "North Hemisphere" was indeed driven by the Apodiformes, Charadriiformes and Galliformes for birds, which are non-Passeriformes (Figure S4B), and by the Rodentia and Soricomorpha for mammals (Figure S4C).

Interestingly, varying the spatial extent of the species pool to estimate relative phylogenetic diversity did not clearly change the overall patterns (Figure 2). There were strong consistencies between the results obtained with the global and hemispheric species pools. Despite few notable exceptions (South America for both birds and mammals), the relationships between rPD and NPP was similarly negative or positive (i.e. US for mammals and North America for birds). For South America, there was a drastic shift from a strong negative to a strong positive relationship between rPD and NPP for both birds and mammals. For amphibians, the results did not differ much across the three spatial extent of the species pool. Only for the zoogeographic species pool, the overall 


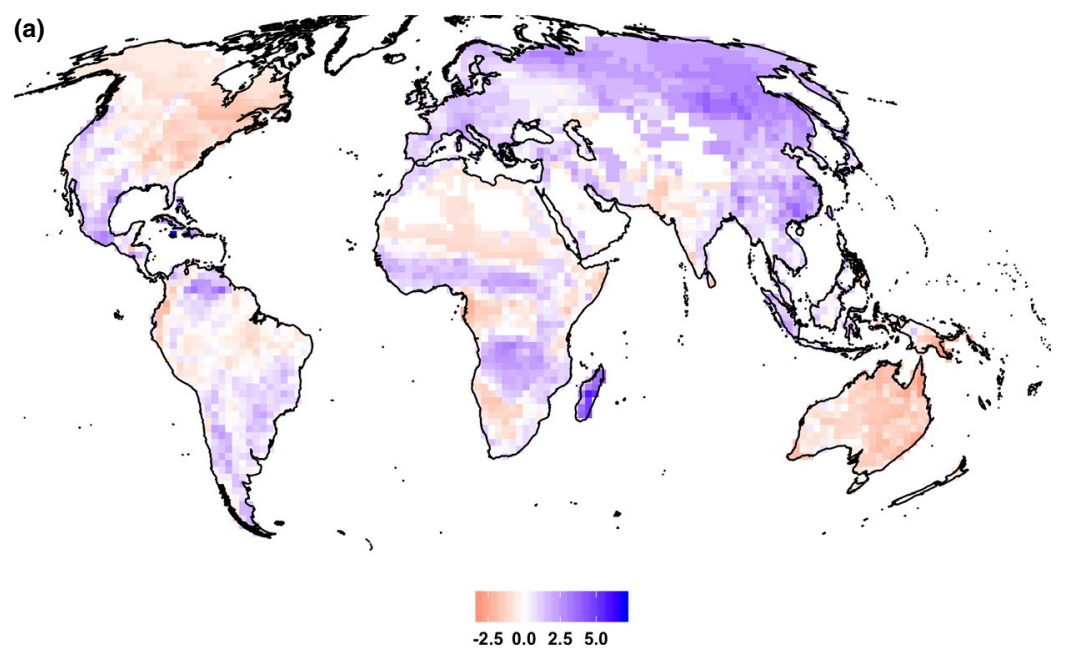

(b)

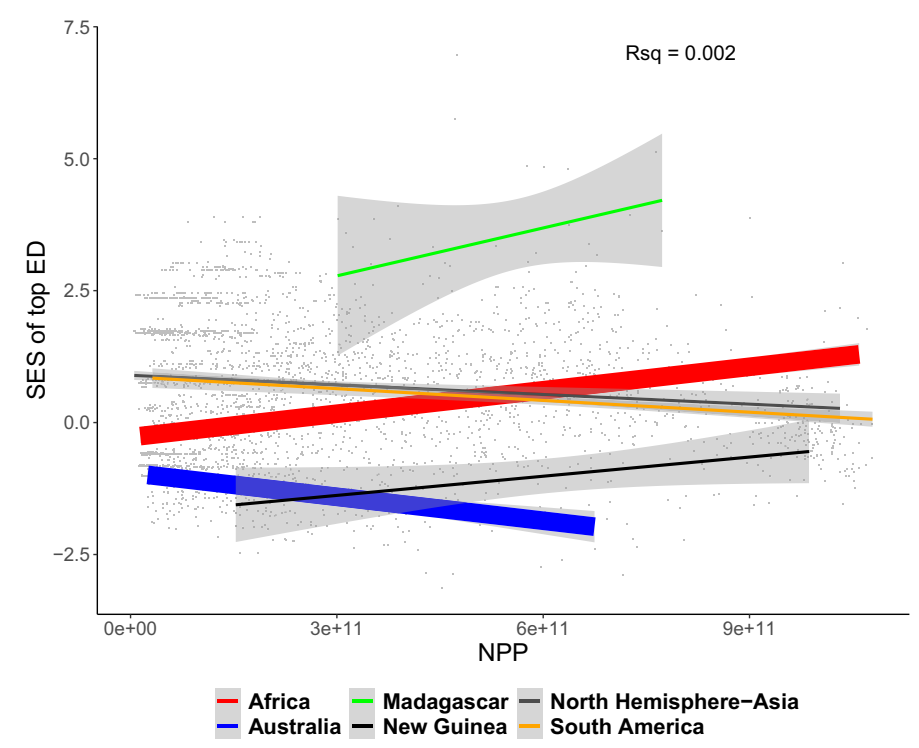

FIG URE 4 Maps of standardized effect size of richness of the top 25\% evolutionarily most distinct species (SES of top ED) and the relationships with net primary productivity (NPP). A-B: amphibians, C-D: birds, E-F: mammals. Plots represent the global relationship estimated for the available trees (100 for birds and mammals) represented as grey dots, while different colours represent the relationships for the different zoogeographic regions. The width of the lines is proportional to the (mean) $R$ square of the relationship (narrow: $R^{2} \leq 0.1$, medium: $0.1<R^{2}<0.3$, large: $R^{2} \geq 0.3$ ). The grey shading around the regression lines represents the $95 \%$ confidence intervals of the regressions. The distributions of the zoogeographic regions are presented in Figure S2

estimated relationships between rPD and NPP were rather weak in most cases, while still generally consistent with the overall pattern calculated with the global species pool (Figure 2). Therefore, we will only present results from the global species pool for all further analyses.

The analysis of the relationship between NPP and the standardized effect sizes of the top $25 \%$ species regarding evolutionary distinctiveness (SES of top ED) and of the top 25\% fastest species-level lineage diversification rates (SES of top DR) (both measured on the global phylogenies of the three clades) allows to evaluate whether regions of high NPP also hold more evolutionarily distinct species and more species with higher diversification rates than expected (cf. Table 1). Both measures reveal strong relationships with NPP for birds and mammals but not for amphibians (Figures 3 and 4, Figure S5 and S6 for the general trends). For the former two groups, and consistently across zoogeographical regions, areas of high NPP harbour fewer species than expected among the top DR (Figure 3, Figure S5). Interestingly, for the three groups, areas with more species than expected from the top DR are only found in the Northern Hemisphere (with few exceptions in extreme west of South Americas) (Figure 3). Reciprocally, more species than expected from the top ED are found with increasing NPP (Figure 4, Figure S6). In general, striking differences exist in the distribution of SES of top ED and SES of top DR for both birds and mammals (Figures 3 and 4, Figure S5 and S6), while this relationship is not as clear when considering the absolute richness of top ED and DR (Figure S7). For instance, for birds, central Africa and Madagascar, Indonesia and Australia were hotspots of evolutionary distinctiveness (with respect to species richness) 


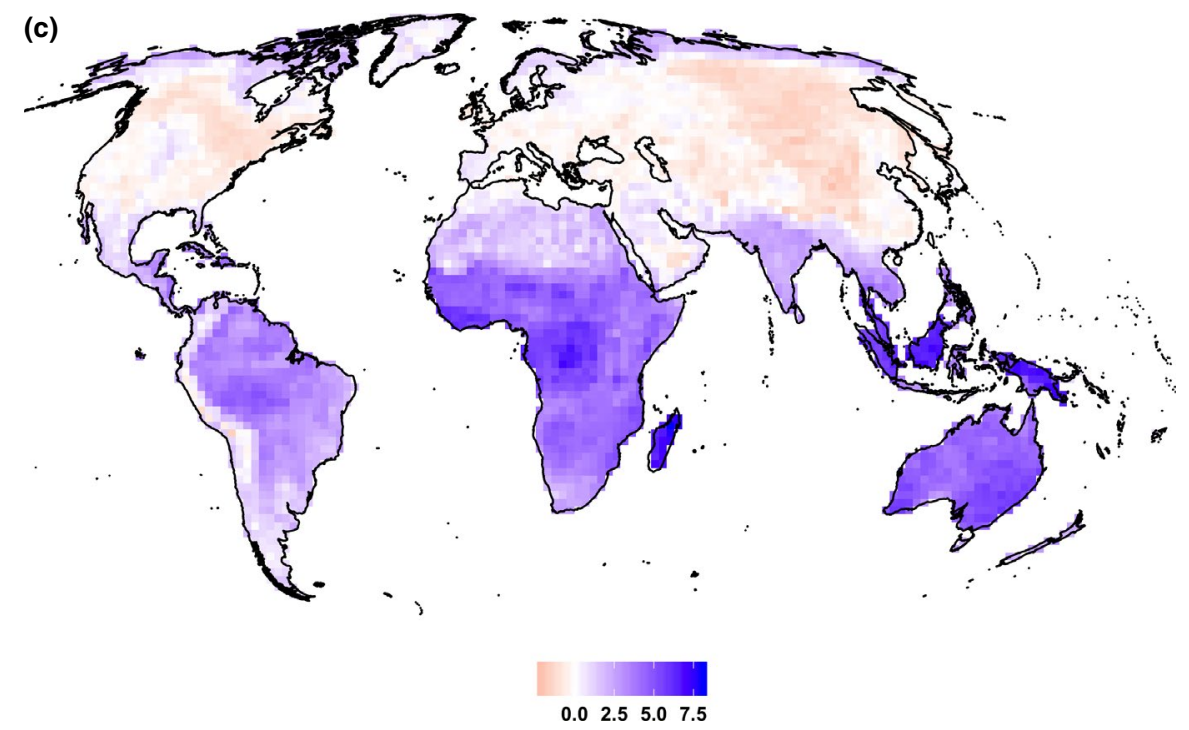

(d)

FIGURE 4 (Continued)

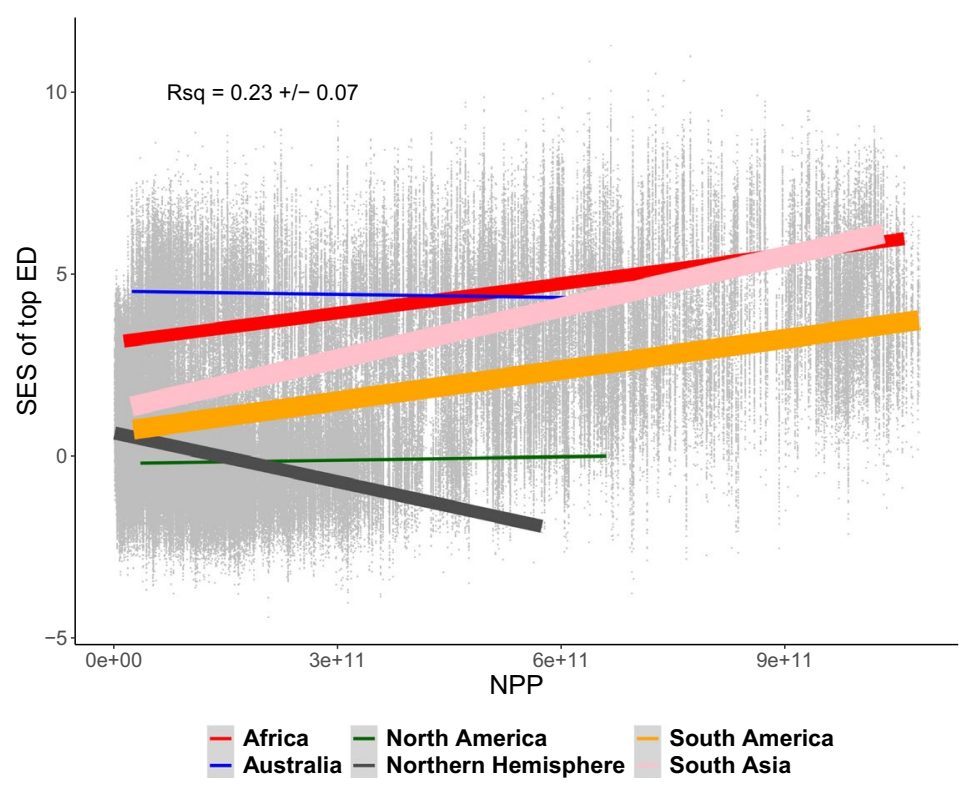

but also coldspots of species-level lineage diversification rates (see Figure S7 for the absolute richness). A similar pattern emerged for mammals, where South America (i.e. the Amazonian forest), Australia and Southern Africa (and Madagascar) were hotspots of evolutionary distinctiveness (with respect to species richness) but coldspots of species-level lineage diversification rates (see Figure S7 for the absolute richness). However, despite slight differences in the relative numbers, the distribution of the two metrics was relatively similar between the two groups. For amphibians, the relationships were more homogenous except for the North Hemisphere, where North America hosts a high proportion of top DR but a low proportion of top ED. The opposite pattern emerges for Northern Europe and Russia (Figures 3 and 4).

\section{4 | DISCUSSION}

In this paper, we test if the commonly observed positive species richness-productivity relationship also holds for phylogenetic diversity, the richness of the top most evolutionarily distinct species and the richness of the top highest species-level lineage diversification rates. After controlling for species richness, we found that regions with higher productivity harbour relatively lower phylogenetic diversity, have an unexpectedly high number of evolutionarily distinct species and an unexpectedly low number of species belonging to rapidly diversifying clades.

These seemingly contradictory results provide new insights into the processes that drive the relationship between vertebrate 


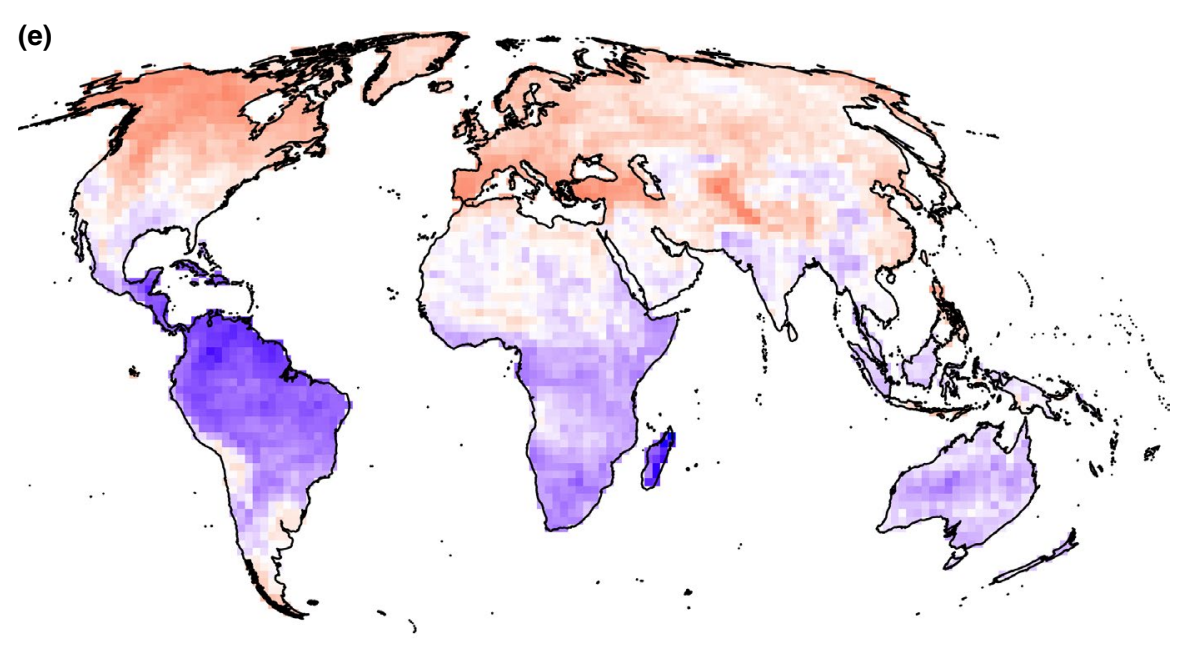

(f)

FIGURE 4 (Continued)

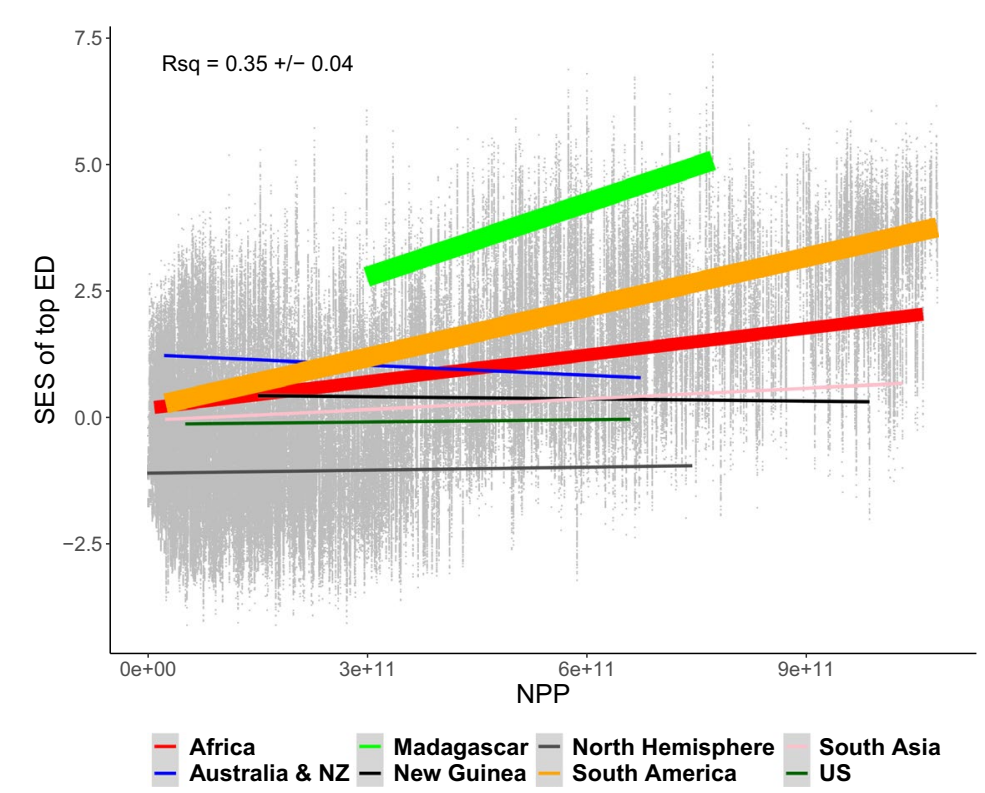

diversity distribution and ecosystems' primary productivity. The observation that highly productive sites harbour much lower rPD scores than expected suggests that elevated NPP (a) facilitates radiations in certain parts of the tree of life, and/or (b) allows the coexistence of closely related species (Evans et al., 2005). However, the relatively low number of species belonging to rapidly diversifying clades in sites of high NPP suggests that rapid diversification might not necessarily be a mechanism that drives the relationship between rPD and NPP (see also Schluter, 2016). Rather, more local ecological processes that we cannot capture at our coarse resolution (filtering or niche partitioning) could be the key in structuring assemblages, at least in high NPP regions. Interestingly, those regions also harbour a higher than expected richness in evolutionarily most distinct species, suggesting that extinction might be reduced under these conditions. This finding is consistent with the hypothesis that the greater combined age and expansion of highly productive regions (usually tropical forest) have facilitated greater species accumulations without necessarily facilitating greater rates of speciation, yet by simply packing more species per unit of space and by a reduced extinction rate (Belmaker \& Jetz, 2015; Jetz et al., 2012).

Low NPP regions harbour relatively high rPD, while having an unexpectedly low number of evolutionarily distinct species and a high number of species belonging to clades with high diversification rates. This means that these areas harbour phylogenetically relatively distant species (e.g. sister species are unlikely to occur in the same pixel), but that these species belong to different disproportionately rapidly diversifying clades. Areas of high diversification rates are found throughout the Northern Hemisphere and the southwest of the South America zoogeographical regions 
(Figure 3, see also Jetz et al., 2012). Those areas are known to host several of the rapidly diversifying clades (e.g. warblers, gulls, some rodent groups), have all been characterized by strong climatic fluctuations from the Pliocene to the present, have generally lower NPP than tropical areas, and were mostly glaciated and experienced the fastest climate change during the last 40,000 years. In other words, the composition of these regions is the result of a recent assembly, rather than in-situ evolution. Interestingly, most species in these low NPP regions have very broad ranges. We could hypothesize that low NPP regions were recolonized by certain distantly related but rapidly diversifying clades from more productive areas that have evolved broad niches and are better adapted to cold/less productive environments (Wiens, Graham, Moen, Smith, \& Reeder, 2006). None of these mechanisms are mutually exclusive and their relative importance may likely vary with temporal and spatial scales.

In the era of Big Data, it becomes clear that long standing hypotheses and descriptive analyses need to be revisited in light of the increasing availability of data on species distribution and their phylogenetic relationships. Here, we build on the most up-to-date macroecological data for three vertebrate groups and analysed the relationships between their evolutionary history and NPP of ecosystems. Our analysis should eventually be complemented with a more detailed modelling of diversification rates (Rabosky et al., 2018; Schluter \& Pennell, 2017). Of course, a part of the non-explained variance in the regression analyses is likely due to the effects of other environmental variables (e.g. temperature) and could lead to more in-depth analyses to tease apart their effects (but see Belmaker \& Jetz, 2015). We acknowledge that our analyses may suffer to some degree from the coarse resolution of both distribution and phylogenetic data. In order to obtain more robust results, the same type of analyses should be repeated at much higher resolution (perhaps using a combination of IUCN and GBIF data) to more rigorously test for niche packing which is rather difficult at a $200 \mathrm{~km}$ resolution and with more reliable phylogenetic trees. The amphibian phylogeny is for instance based on an incomplete set of species and lack strong support in several places. However, we are confident that our analyses could pave the way for more in-depth analyses in the coming years given the rise of available data, to more formally test the effects of scale (Chase, 2010), community assembly processes and energy constraints (Barnes et al., 2014).

\section{ACKNOWLEDGEMENTS}

W.T., T.M., L.J.P and N.E.Z. received funding from the ERA-Net BiodivERsA - Belmont Forum, with the national funder Agence Nationale pour la Recherche (ANR-18-EBI4-0009) and Swiss National Foundation (20BD21_184131/1), part of the 2018 Joint call BiodivERsA-Belmont Forum call (project 'FutureWeb'). This research is supported by the French Foundation for Research on Biodiversity (FRB; www.fondationbiodiversite.fr) in the context of the CESAB project 'Causes and consequences of functional rarity from local to global scales' (FREE)

\section{ORCID}

Wilfried Thuiller (iD https://orcid.org/0000-0002-5388-5274

Gentile Francesco Ficetola (iD https://orcid.org/0000-0003-3414-5155

\section{REFERENCES}

Allen, A. P., \& Gillooly, J. F. (2006). Assessing latitudinal gradients in speciation rates and biodiversity at the global scale. Ecology Letters, 9, 947-954. https://doi.org/10.1111/j.1461-0248.2006. 00946.x

Barnes, A. D., Jochum, M., Mumme, S., Haneda, N. F., Farajallah, A., Widarto, T. H., \& Brose, U. (2014). Consequences of tropical land use for multitrophic biodiversity and ecosystem functioning. Nature Communications, 5. https://doi.org/10.1038/ncomms6351

Belmaker, J., \& Jetz, W. (2015). Relative roles of ecological and energetic constraints, diversification rates and region history on global species richness gradients. Ecology Letters, 18, 563-571. https://doi. org/10.1111/ele.12438

Bertness, M. D., \& Callaway, R. (1994). Positive interactions in communities. Trends in Ecology \& Evolution, 9, 191-193. https://doi. org/10.1016/0169-5347(94)90088-4

Bininda-Emonds, O. R. P., Cardillo, M., Jones, K. E., MacPhee, R. D. E., Beck, R. M. D., Grenyer, R., ... Purvis, A. (2007). The delayed rise of present-day mammals. Nature, 446, 507-512. https://doi. org/10.1038/nature05634

Brown, J. H. (2014). Why are there so many species in the tropics? Journal of Biogeography, 41, 8-22. https://doi.org/10.1111/jbi.12228

Chase, J. M. (2010). Stochastic community assembly causes higher biodiversity in more productive environments. Science, 328, 1388-1391. https://doi.org/10.1126/science.1187820

Currie, D. J., Mittelbach, G., Cornell, H. V., Field, R., Guégan, J.-F., Hawkins, B. A., ... Turner, J. R. G. (2004). Predictions and tests of climate-based hypotheses of broad-scale variation in taxonomic richness. Ecology Letters, 7, 1121-1134. https://doi. org/10.1111/j.1461-0248.2004.00671.x

Evans, H., Straw, N., \& Watt, A. (2002). Climate change: Implications for insect pests. In M. Broadmeadow (Ed.), Climate change: Impacts on UK forests (pp. 99-118). Forestry Commission.

Evans, K. L., Warren, P. H., \& Gaston, K. J. (2005). Species-energy relationships at the macroecological scale: A review of the mechanisms. Biological Reviews, 80, 1-25. https://doi.org/10.1017/S146479310 4006517

Faith, D. P. (1992). Conservation evaluation and phylogenetic diversity. Biological Conservation, 61, 1-10. https://doi. org/10.1016/0006-3207(92)91201-3

Faith, D. P. (2002). Quantifying biodiversity: A phylogenetic perspective. Conservation Biology, 16, 248-252. https://doi. org/10.1046/j.1523-1739.2002.00503.x

Ficetola, G. F., Rondinini, C., Bonardi, A., Katariya, V., Padoa-Schioppa, E., \& Angulo, A. (2014). An evaluation of the robustness of global amphibian range maps. Journal of Biogeography, 41, 211-221. https:// doi.org/10.1111/jbi.12206

Fritz, S. A., Bininda-Emonds, O. R. P., \& Purvis, A. (2009). Geographical variation in predictors of mammalian extinction risk: Big is bad, but only in the tropics. Ecology Letters, 12, 538-549. https://doi. org/10.1111/j.1461-0248.2009.01307.x

Fritz, S. A., Eronen, J. T., Schnitzler, J., Hof, C., Janis, C. M., Mulch, A., ... Graham, C. H. (2016). Twenty-million-year relationship between 
mammalian diversity and primary productivity. Proceedings of the National Academy of Sciences of the United States of America, 113, 10908-10913. https://doi.org/10.1073/pnas.1602145113

Holt, B. G., Lessard, J.-P., Borregaard, M. K., Fritz, S. A., Araújo, M. B., Dimitrov, D., ... Rahbek, C. (2013). An update of Wallace's zoogeographic regions of the world. Science, 339, 74-78. https://doi. org/10.1126/science.1228282

Hurlbert, A. H., \& Jetz, W. (2007). Species richness, hotspots, and the scale dependence of range maps in ecology and conservation. Proceedings of the National Academy of Sciences of the United States of America, 104, 13384-13389. https://doi.org/10.1073/pnas.07044 69104

Imhoff, M. L., \& Bounoua, L. (2006). Exploring global patterns of net primary production carbon supply and demand using satellite observations and statistical data. Journal of Geophysical ResearchAtmospheres, 111(D22). https://doi.org/10.1029/2006JD007377

Imhoff, M. L., Bounoua, L., Ricketts, T., Loucks, C., Harriss, R., \& Lawrence, W. T. (2004). Global patterns in human consumption of net primary production. Nature, 429, 870-873. https://doi.org/10.1038/natur e02619

Isaac, N. J. B., Redding, D. W., Meredith, H. M., \& Safi, K. (2012). Phylogenetically-Informed priorities for amphibian conservation. PLoS ONE, 7(8), e43912. https://doi.org/10.1371/journ al.pone.0043912

Jetz, W., \& Fine, P. V. A. (2012). Global gradients in vertebrate diversity predicted by historical area-productivity dynamics and contemporary environment. PLoS Biology, 10(3), e1001292. https://doi. org/10.1371/journal.pbio.1001292

Jetz, W., Thomas, G. H., Joy, J. B., Hartmann, K., \& Mooers, A. O. (2012). The global diversity of birds in space and time. Nature, 491, 444-448. https://doi.org/10.1038/nature11631

Kissling, W. D., Baker, W. J., Balslev, H., Barfod, A. S., Borchsenius, F., Dransfield, J., ... Svenning, J.-C. (2012). Quaternary and preQuaternary historical legacies in the global distribution of a major tropical plant lineage. Global Ecology and Biogeography, 21, 909-921. https://doi.org/10.1111/j.1466-8238.2011.00728.x

Lavergne, S., Mouquet, N., Thuiller, W., \& Ronce, O. (2010). Biodiversity and climate change: Integrating evolutionary and ecological responses of species and communities. Annual Review of Ecology, Evolution and Systematics, 41, 321-350. https://doi.org/10.1146/ annurev-ecolsys-102209-144628

Mazel, F., Renaud, J., Guilhaumon, F., Mouillot, D., Gravel, D., \& Thuiller, W. (2015). Mammalian phylogenetic diversity area relationships at a continental scale. Ecology, 96, 2814-2822. https://doi. org/10.1890/14-1858.1

Nyakatura, K., \& Bininda-Emonds, O. R. P. (2012). Updating the evolutionary history of Carnivora (Mammalia): A new species-level supertree complete with divergence time estimates. BMC Biology, 10. https ://doi.org/10.1186/1741-7007-10-12

Pollock, L. J., Thuiller, W., \& Jetz, W. (2017). Large conservation gains possible for global biodiversity facets. Nature, 546, 141-144. https:// doi.org/10.1038/nature22368

Rabosky, D. L., Chang, J., Title, P., Cowman, P. F., Sallan, L., Friedman, M., ... Alfaro, M. E. (2018). An inverse latitudinal gradient in speciation rate for marine fishes. Nature, 559, 392-395. https://doi. org/10.1038/s41586-018-0273-1

Redding, D. W., Mazel, F., \& Mooers, A. Ø. (2014). Measuring evolutionary isolation for conservation. PLoS ONE, 9(12), e113490. https://doi. org/10.1371/journal.pone.0113490

Rosenzweig, M. L. (1995). Species diversity in space and time. Cambridge, UK: Cambridge University Press.

Schemske, D. W., Mittelbach, G. G., Cornell, H. V., Sobel, J. M., \& Roy, K. (2009). Is there a latitudinal gradient in the importance of biotic interactions? Annual Review of Ecology Evolution and Systematics, 40, 245-269. https://doi.org/10.1146/annurev.ecols ys.39.110707.173430

Schluter, D. (2016). Speciation, ecological opportunity, and latitude. American Naturalist, 187, 1-18. https://doi.org/10.1086/684193

Schluter, D., \& Pennell, M. W. (2017). Speciation gradients and the distribution of biodiversity. Nature, 546, 48-55. https://doi.org/10.1038/ nature22897

Storch, D., Bohdalková, E., \& Okie, J. (2018). The more-individuals hypothesis revisited: The role of community abundance in species richness regulation and the productivity-diversity relationship. Ecology Letters, 21, 920-937. https://doi.org/10.1111/ele.12941

Tsirogiannis, C., \& Sandel, B. (2016). PhyloMeasures: A package for computing phylogenetic biodiversity measures and their statistical moments. Ecography, 39, 709-714. https://doi.org/10.1111/ecog.01814

Weir, J. T., \& Schluter, D. (2007). The latitudinal gradient in recent speciation and extinction rates of birds and mammals. Science, 315, 15741576. https://doi.org/10.1126/science.1135590

Wiens, J. J., Graham, C. H., Moen, D. S., Smith, S. A., \& Reeder, T. W. (2006). Evolutionary and ecological causes of the latitudinal diversity gradient in hylid frogs: Treefrog trees unearth the roots of high tropical diversity. American Naturalist, 168, 579-596. https://doi. org/10.1086/507882

Wright, D. H., Currie, D. J., \& Maurer, B. A. (1993). Energy supply and patterns of species richness on local and regional scales. In R. E. Ricklefs \& D. Schluter (Eds.), Species diversity in ecological communities: Historical and geographical perspectives (pp. 66-74). Chicago: Chicago University Press.

Wright, S. D., \& Rohde, K. (2013). Energy and spatial order in niche and community. Biological Journal of the Linnean Society, 110, 696-714. https://doi.org/10.1111/bij.12141

\section{BIOSKETCH}

Wilfried Thuiller is broadly interested in merging concepts and theories from biogeography, community ecology and spatial network ecology through the use of state-of-the-art statistical and mathematical approaches.

Author contribution: WT and DG conceived the ideas with the help of FM, TM and LJP. WT compiled all data and ran the analyses, prepared the figures, wrote the initial draft and led the revisions of the paper. All authors contributed to interpreting the results and to writing the manuscript.

\section{SUPPORTING INFORMATION}

Additional supporting information may be found online in the Supporting Information section at the end of the article.

How to cite this article: Thuiller W, Gravel D, Ficetola GF, et al. Productivity begets less phylogenetic diversity but higher uniqueness than expected. J Biogeogr. 2020;47:44-58. https:// doi.org/10.1111/jbi.13630 